\title{
Type of e-liquid vaped, poly-nicotine use and nicotine dependence symptoms in young adult e-cigarette users: a descriptive study
}

Erika N. Dugas ${ }^{1}$, Marie-Pierre Sylvestre ${ }^{1,2}$ and Jennifer $\mathrm{O}^{\prime}$ Loughlin $^{1,2^{*}}$ (1)

\begin{abstract}
Background: Data are lacking on type of e-liquid vaped among e-cigarette users. Further, few studies assess all sources of nicotine used by e-cigarette users to assess whether poly-nicotine use relates to nicotine dependence (ND). The objectives were to describe young adult e-cigarette users by: (i) type of e-liquid vaped; (ii) poly-nicotine use; (iii) ND symptoms; and (iv) attempts to quit conventional cigarettes.
\end{abstract}

Methods: Data were available in cycle 23 of a longitudinal investigation on the natural course of cigarette smoking and ND. A total of 775 young adults (44\% male; mean (SD) age 30.5(1.0)) completed mailed self-report questionnaires in 2017-20.

Results: Of 775 participants, 149 (19.2\%) reported past-year e-cigarette use. Overall, 55.0\% of e-cigarette users had used cannabis-containing e-liquid (31.5\% vaped cannabis e-liquid exclusively); $50.4 \%$ used nicotine-containing e-liquid (23.5\% vaped nicotine e-liquid exclusively); and 39.9\% used e-liquid without nicotine (8.7\% vaped e-liquid without nicotine exclusively). Most e-cigarette users (82.6\%) used other nicotine-containing products including conventional cigarettes (72.5\%); $60.8 \%$ reported ND symptoms, rising to $79.4 \%$ among those who vaped nicotine-containing e-liquid. Finally, 29.0\% tried to quit conventional cigarettes using e-cigarettes in the past-year, but only $16.7 \%$ found them helpful.

Conclusions: E-cigarettes now appear to appeal to a broader market than smokers who want to quit. More than half of young adult e-cigarette users vaped cannabis-containing e-liquid in the past year while only one-quarter had used e-cigarettes to assist with cessation. Most e-cigarette users used multiple nicotine-containing substances (including combustible cigarettes) which were associated with reports of ND symptoms.

Keywords: Young adults, E-cigarettes, Cigarettes, Nicotine, Nicotine dependence, Cannabis

\footnotetext{
* Correspondence: jennifer.oloughlin@umontreal.ca

'Centre de recherche du centre hospitalier de I'Université de Montréal (CRCHUM), 850 Saint-Denis (S03-468), Montreal, Quebec H2X 0A9, Canada ${ }^{2}$ Department of Social and Preventive Medicine, Université de Montréal, Montreal, QC, Canada
}

C The Author(s). 2020 Open Access This article is licensed under a Creative Commons Attribution 4.0 International License, which permits use, sharing, adaptation, distribution and reproduction in any medium or format, as long as you give appropriate credit to the original author(s) and the source, provide a link to the Creative Commons licence, and indicate if changes were made. The images or other third party material in this article are included in the article's Creative Commons licence, unless indicated otherwise in a credit line to the material. If material is not included in the article's Creative Commons licence and your intended use is not permitted by statutory regulation or exceeds the permitted use, you will need to obtain permission directly from the copyright holder. To view a copy of this licence, visit http://creativecommons.org/licenses/by/4.0/ The Creative Commons Public Domain Dedication waiver (http://creativecommons.org/publicdomain/zero/1.0/) applies to the data made available in this article, unless otherwise stated in a credit line to the data. 


\section{Background}

E-cigarette use is common in Canada. In 2017, 23-29\% of persons age 15-34 years reported ever trying ecigarettes and 6\% reported daily use [1]. Between 2017 and 2018, a dramatic 74\% increase in past-month use was observed among 16-19-year-old Canadians [2]. In the same time period, current e-cigarette use increased 46\% in 18-24-year-old Americans [3]. Because ecigarette use is escalating among adolescents and young adults $[1,2]$, there is growing concern that the tobacco industry is targeting young people $[4,5]$ with e-cigarette marketing strategies that appeal to this age group including colorful packaging, a significant online presence [4-6], celebrity endorsements [5] and more than 7000 flavors, most of which are fruit- or confectionary-flavored [7]. New e-cigarette products targeting young people appear on the market with regularity. For example, ecigarettes designed specifically to vape cannabis have become increasingly popular [8-11] and are associated with lower perceived risk [11] and increased use [12]. Although there is an extensive literature on e-cigarettes and smoking cessation, the evidence that e-cigarettes with or without nicotine help smokers quit remains inconsistent in systematic reviews [13-16] and randomized controlled trials [17-20]. Additional concerns include the presence of nicotine in e-cigarettes which could hinder cessation efforts and delay cessation [4], the impact of e-cigarette use on re-normalizing smoking [4], smoking re-uptake in former smokers [4], and growing evidence that ecigarettes might be a gateway to cigarette smoking initiation in youth $[4,21-23]$. We add poly-nicotine use (i.e., use of multiple nicotine-containing substances concurrently) to this list. Poly-nicotine use is common in young people $[1,4,24,25]$; it is estimated that only $1.4 \%$ of U.S. adults are sole e-cigarette users [26].

More recently, there has been widespread alarm about vaping-induced respiratory injuries in the US [27] and Canada [28]. A US Center for Disease Control (CDC) special announcement in October 2019 [29] reported that most lung injury cases involved tetrahydrocannabinol (THC)-containing products and its recommendations included, among others, that: people should not vape products containing THC or modify e-liquid; using any type of e-cigarette is unsafe; nicotine is highly addictive and can harm the developing brain; and ecigarettes should not be used by youth or young adults. In light of this report, it is critical to better describe young e-cigarette users and in particular, whether eliquid used contain cannabis. In addition, few studies assess all sources of nicotine used by e-cigarette users and assess whether poly-nicotine use relates to nicotine dependence. The objectives of this study were to describe young adult e-cigarette users by: (i) type of e-liquid vaped in the past year (i.e., with nicotine, without nicotine, with cannabis); (ii) poly-nicotine use (i.e., concurrent use of multiple nicotine-containing substances); (iii) nicotine dependence (ND) symptoms; and (iv) attempts to quit conventional cigarettes using e-cigarettes.

\section{Methods}

Data were drawn from the Nicotine Dependence in Teens (NDIT) study, a longitudinal investigation on the natural course of nicotine dependence of 1294 students recruited in 1999-2000 from all grade 7 classes in a purposive sample of ten Montreal-area high schools [30]. NDIT used a school-based sampling strategy to recruit participants. High schools $(n=13)$ in or near Montreal were selected in consultation with local school boards and school principals to include a mix of: (i) Frenchand English-language schools; (ii) urban, suburban and rural schools; and (iii) schools located in high, moderate and low socioeconomic status neighborhoods. Private schools were excluded. Two schools were excluded because of a low return of parental consent forms, and one school was excluded because school administrators could not guarantee continued participation in NDIT after the first year of the study. The total number of schools retained was 10. All grade 7 students (mean age 12.8 years) in the study schools including special needs students, were invited to take part of the study. Data were collected in self-report questionnaires administered at school every 3-4 months from grade 7 to 11 , and in three cycles post-high school when participants were age $20.4,24.0$ and 30.5 years on average. The current analysis used data collected in 2017-20 when participants were age 30.5 years.

The study was approved by the Ethics Research Committee of the Centre de Recherche du Centre Hospitalier de l'Université de Montréal. Participants provided written informed consent.

\section{Study variables}

E-cigarette liquid - Participants were asked how often (never; less than once a month; 1-3 times per month; 1-6 times per week; every day) in the past 12 months they had used e-cigarettes with nicotine; without nicotine; or to vape marijuana, hash oil, liquid or wax. For several analyses, responses were recoded as no (never)/ yes (all other responses).

Past-year cigarette smokers - Ever smokers were asked to self-identify into one of the following: I have smoked cigarettes, but not at all in the past 12 months; I smoked cigarettes once or a couple of times in the past 12 months; I smoke cigarettes once or a couple of times each month; I smoke cigarettes once or a couple of times each week; I smoke cigarettes every day. Responses were recoded no (I have smoked cigarettes, but not at all in the past 12 months)/yes (all other responses). 
Current smoking was measured by: "During (last month), on how many days did you smoke cigarettes, even just a puff?" Participants were categorized as current smokers (i.e., smoked in the past month) if they responded smoking on one or more days in the past month.

Other tobacco products - Participants were asked how often in the past 12 months they had used: (i) flavored cigarettes or cigarillos; (ii) cigars, pipe, bidis, chewing tobacco and/or snuff; (iii) cigarillos; and (iv) waterpipe. Because of low frequency of use, all products were combined into a single variable called "other tobacco products". Responses were coded yes (i.e., used one or more)/ no (i.e., did not use any).

Cannabis mixed with tobacco - Participants were asked how often (never; less than once a month; 1-3 times per month; 1-6 times per week; every day) in the past 12 months they used marijuana, cannabis or hashish mixed with tobacco?" Responses were recoded no (never)/yes (all other responses).

Number of other nicotine-containing substances used in the past year was the sum of positive responses for conventional cigarettes, other tobacco products and cannabis mixed with tobacco (range 0-3) (excluding ecigarettes with nicotine).

There is evidence that former smokers continue to experience ND symptoms short- and long-term [31, 32]. Further, young never smokers who live in environments with exposure to second- and third-hand smoke report ND symptoms [33, 34]. In this study, questions on perceived ND and cravings were measured among all ever and non-smokers (including never smokers and quitters), whereas withdrawal symptoms was measured in past 3-month smokers only. Perceived (cigarette-related) $N D$ was measured by: "Even if you do not currently smoke cigarettes, how addicted to smoking cigarettes are you ...?" (i) physically; (ii) mentally. Responses (not at all; a little bit; quite; very) were recoded (yes/no) according to whether participants reported any positive response.

Craving was measured by: "Even if you do not currently smoke cigarettes, how often do you ... crave a cigarette?" For analysis, response choices were recoded yes (rarely, sometimes, often)/no (never).

Withdrawal symptoms was measured among ever smokers only by: "When you cut down or stop using cigarettes, or when you are not able to smoke for a long period (like most of the day), how often did you experience ... feeling a strong urge or need to smoke". Responses were recoded yes (rarely, sometimes, often)/no (never). Convergent construct validity of the craving and withdrawal indicators were demonstrated previously against quit attempts and smoking status [35].

Use of e-cigarettes as a cessation aid was measured among ever smokers only by: (i) "Did you ever try any of the following to help you quit smoking cigarettes..." (a) electronic cigarettes with nicotine (yes/no), (b) electronic cigarettes without nicotine. (yes/no); (ii) "If yes, was this in the past 12 months?" (yes, no); and (iii) "Did it help you to quit?" (yes, no). Use of e-cigarettes for cessation with or without nicotine were combined (i.e., yes to at least one) for ever tried, tried in the past year and perception that it helped (yes/no).

Sociodemographic data included age, sex, mother university-educated (yes/no) [36, 37], language spoken at home (French, English, other) and born in Canada (yes/no).

\section{Data analysis}

Descriptive statistics were used to address the study objectives. Analyses were conducted using SPSS, Version 25.0 (IBM Corp. Released 2012. IBM SPSS Statistics for Windows, Version 25.0. Armonk, NY: IBM Corp.).

\section{Results}

E-cigarette data were available for 775 participants $(60 \%$ of 1294 participants at inception). Compared to 519 participants not retained (lost-to-follow-up and those who did not provide data in 2017-20), those retained for analysis were younger at NDIT inception in 1999 and higher proportions were female, Canadian and had universityeducated mothers. Lower proportions had smoked cigarettes or other tobacco products in the past 3 months. There was no difference in language (Table 1$)$.

One-fifth $(19.2 \%)$ of the 775 participants $(n=149)$ reported past-year e-cigarette use, including more males than females $(24.9 \%$ vs $14.7 \% ; p \leq 0.001)$. Among ecigarette users, $50.3 \%$ used e-cigarettes less than once a month; $21.5 \%$ vaped $1-3$ times per month; $16.8 \%$ vaped 1-6 times per week, and $11.4 \%$ vaped every day.

Table 1 Baseline characteristics ${ }^{\mathrm{a}}$ of participants retained and not retained $(n=1294)$. NDIT Study 1999-2020

\begin{tabular}{|c|c|c|c|}
\hline & \multicolumn{2}{|l|}{ Retained } & \multirow{2}{*}{$\begin{array}{l}p \text {-value }{ }^{b} \text { for } \\
\text { difference }\end{array}$} \\
\hline & $\begin{array}{l}\text { Yes } \\
(n=775)\end{array}$ & $\begin{array}{l}\mathrm{No}^{c} \\
(n=519)\end{array}$ & \\
\hline Age, mean (sd) & $12.7(0.5)$ & $12.9(0.7)$ & $\leq 0.001$ \\
\hline Male, \% & 44.0 & 54.4 & $\leq 0.001$ \\
\hline Mother university-educated, \% & 42.3 & 20.6 & $\leq 0.001$ \\
\hline French-speaking, \% & 30.2 & 29.9 & 0.917 \\
\hline Born in Canada, \% & 93.8 & 89.6 & 0.006 \\
\hline Ever smoked, \% & 27.9 & 38.2 & $\leq 0.001$ \\
\hline Used other tobacco products, \% & 8.6 & 12.2 & 0.041 \\
\hline
\end{tabular}

${ }^{\text {a }}$ Measured in cycle 1 (grade 7) in 1999

based on t-tests and chi-square tests. Boldface indicates statistical significance $(p<0.05)$

Includes participants lost-to-follow-up (i.e., participants who dropped out of NDIT) and those who did not provide data in 2017-20 (i.e., participants who did not provide data in 2017-20, but did not drop out of NDIT) 
Two-thirds (63.8\%) of e-cigarette users reported using only one of the three types of e-liquid investigated herein (with nicotine, without nicotine, with cannabis) in the past year, $27.5 \%$ used two types of e-liquid, and $8.7 \%$ had used all three types (Table 2). Overall, $55.0 \%$ of ecigarette users had used cannabis-containing e-liquid (31.5\% vaped cannabis e-liquid exclusively); $50.4 \%$ used nicotine-containing e-liquid $(23.5 \%$ vaped nicotine eliquid only); and $39.9 \%$ used e-liquid without nicotine (8.7\% vaped e-liquid without nicotine exclusively).

Most e-cigarette users $(82.6 \%)$ had used at least one other nicotine-containing substance (i.e., conventional cigarettes, other tobacco products, cannabis mixed with tobacco) in the past year (Table 3). The mean number of other nicotine-containing substances was highest among participants who vaped nicotine-containing e-liquid. The most frequently used other nicotine-containing substance was conventional cigarettes - $72.5 \%$ of all ecigarette users had smoked cigarettes in the past year. This proportion was highest among young adults who vaped e-liquid with nicotine, ranging from $84.6 \%$ (among those who used three e-liquid products) to 100\% (among those who vaped e-liquid with nicotine or cannabis) (Table 3).

Two-thirds $(60.8 \%)$ of participants perceived that they were nicotine dependent, $57.8 \%$ reported craving and $58.1 \%$ had withdrawal symptoms. Compared to participants who vaped e-liquid without nicotine or with cannabis, much higher proportions who vaped e-liquid with nicotine reported ND symptoms (Table 3 ).

Less than half (44.2\%) of e-cigarette users had tried to quit conventional cigarettes using e-cigarettes at least once lifetime (Table 4). Of those who had tried, 80.3\% were current smokers (i.e., reported smoking in the past month) at age 30.5. In the past year, $29.0 \%$ had used ecigarettes to help them quit, $16.7 \%$ found them helpful, but $80.0 \%$ were still smoking (i.e., were current smokers).

Table 2 E-liquid used in the past-year by young adult ecigarette users. NDIT Study 2017-20

\begin{tabular}{lcc}
\hline E-liquid & $\mathrm{n}$ & Total $^{\mathrm{a}} \%$ \\
\hline Total & 149 & 100.0 \\
One e-liquid & 95 & 63.8 \\
With nicotine & 35 & 23.5 \\
Without nicotine & 13 & 8.7 \\
For cannabis & 47 & 31.5 \\
Two e-liquids & 41 & 27.5 \\
With and without nicotine & 19 & 12.8 \\
With nicotine and for cannabis & 8 & 5.4 \\
Without nicotine and for cannabis & 14 & 9.4 \\
Three e-liquids & 13 & 8.7 \\
\hline
\end{tabular}

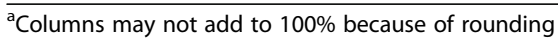

Of those who perceived that e-cigarettes were helpful as a cessation aid, $65.2 \%$ were still smoking (i.e., were current smokers). Compared to participants who vaped e-liquid without nicotine or with cannabis, higher proportions of those who used e-liquid with nicotine had attempted to quit, and reported that they were helpful.

\section{Discussion}

Mirroring the prevalence in Canada and consistent with extant studies [1, 4, 38], 19\% of young adults in this study had used e-cigarettes in the past year, including relatively more males than females. Also concordant with previous reports $[1,4,24,25]$, most e-cigarette users smoked conventional cigarettes and two-thirds reported ND symptoms, with the proportion increasing to $80 \%$ among those who vaped nicotine-containing eliquid exclusively. Only one-quarter of cigarette users had used e-cigarettes to quit in the past year. Given the popularity of vaping cannabis [39, 40] and recent vaping-induced respiratory injuries [27-29], it is critical to better understand what e-cigarette users vape and the reasons that young adults choose these products. We speculate that the reasons differ by e-liquid used.

Reflecting rapid adaptation of the market to emerging tobacco-related products, cannabis-containing e-liquid was the most frequently reported product used in ecigarettes in this current study. The $32 \%$ of exclusive cannabis vapers (among all e-cigarettes users) in our study was markedly higher than the $7 \%$ reported by Kenne et al. (2017) [8] among US college students in 2017. The apparent increasing popularity of vaping cannabis may relate to vaporizers facilitating discrete use of cannabis - the device can be easily concealed, it has the appearance of regular e-cigarettes, and it produces near odorless vapor $[10,11,41]$. Vape from cannabis is described as more palatable [11] and because vaporized cannabis products can deliver higher concentrations of THC than conventional cannabis, it is associated with a stronger "high" [11]. Finally, users may believe that vaping cannabis is less harmful than traditional ways of consuming cannabis. Half (49\%) of those who vaped cannabis exclusively in our study, smoked conventional cigarettes and $43 \%$ reported ND symptoms. Only $2 \%$ of exclusive cannabis vapers had tried to quit conventional cigarettes in the past year.

E-liquid with nicotine was the second most frequently vaped e-liquid. Half of those who used e-liquid with nicotine exclusively (i.e., $54.3 \%$ of 35 ) had used ecigarettes as a cessation aid in the past year, but $60 \%$ of the 10 participant who found them helpful were current smokers. Most participants (79-88\%) who used nicotinecontaining e-liquid reported ND symptoms, similar to the $89 \%$ of long-term vapers reported by Etter et al. (2019) [42]. The new generation of e-liquid often contain 
Table 3 Use of other nicotine-containing substances ${ }^{a}$ and ND according to e-liquid. NDIT Study 2017-20

\begin{tabular}{|c|c|c|c|c|c|c|c|}
\hline E-liquid & $n$ & $\begin{array}{l}\text { Used } \geq 1 \text { other } \\
\text { nicotine-containing } \\
\text { substance in }^{a} \text { past year } \\
\%\end{array}$ & $\begin{array}{l}\text { No. other nicotine- } \\
\text { containing substances } \\
\text { in past year }{ }^{\mathrm{a}} \text { mean (sd) }\end{array}$ & $\begin{array}{l}\text { Used conventional } \\
\text { cigarettes in past year } \\
\%\end{array}$ & $\begin{array}{l}\text { Perceived nicotine } \\
\text { dependence } \\
\%\end{array}$ & $\begin{array}{l}\text { Craving } \\
\%\end{array}$ & $\begin{array}{l}\text { Withdrawal } \\
\text { symptoms } \\
\%\end{array}$ \\
\hline Total & 149 & 82.6 & $1.6(1.0)$ & 72.5 & 60.8 & 57.8 & 58.1 \\
\hline One e-liquid & 95 & 75.8 & $1.3(1.0)$ & 64.2 & 54.3 & 52.7 & 56.6 \\
\hline With nicotine only & 35 & 91.4 & $1.5(0.9)$ & 88.6 & 79.4 & 82.4 & 74.3 \\
\hline Without nicotine only & 13 & 76.9 & $1.2(1.0)$ & 53.8 & 30.8 & 25.0 & 25.0 \\
\hline For cannabis only & 47 & 63.8 & $1.3(1.1)$ & 48.9 & 42.6 & 38.3 & 47.5 \\
\hline Two e-liquids & 41 & 95.1 & $1.9(0.8)$ & 87.8 & 68.3 & 65.9 & 60.0 \\
\hline With and without nicotine & 19 & 100.0 & $1.9(0.7)$ & 94.7 & 84.2 & 78.9 & 84.2 \\
\hline $\begin{array}{l}\text { With nicotine and for } \\
\text { cannabis }\end{array}$ & 8 & 100.0 & $2.0(0.9)$ & 100.0 & 87.5 & 87.5 & 62.5 \\
\hline $\begin{array}{l}\text { Without nicotine and } \\
\text { for cannabis }\end{array}$ & 14 & 85.7 & $1.7(1.0)$ & 71.4 & 35.7 & 35.7 & 23.1 \\
\hline Three e-liquids & 13 & 92.3 & $2.2(0.9)$ & 84.6 & 84.6 & 69.2 & 61.5 \\
\hline
\end{tabular}

ancludes conventional cigarettes, other tobacco products (cigarillos, cigars, pipes, bidis, chewing tobacco, snuff, waterpipe) and cannabis mixed with tobacco ${ }^{b} 11$ participants who had never smoked cigarettes (verified in data collection cycles 1-22) were excluded

nicotine salts which permits easier inhalation of higher levels of nicotine without the harsh taste [43], and nicotine concentrations in e-liquid have increased in the last decade [44]. While the European Union imposed a nicotine cap of $20 \mathrm{mg} / \mathrm{ml}$, Canada has a limit of $66 \mathrm{mg} / \mathrm{mL}$ [45] and there is currently no limit in the US $[46,47]$. Based on our data, users of nicotine-containing e-liquid may be seeking nicotine in a variety of nicotine-containing substances, possibly to assuage ND symptoms or for the mood-altering effects of nicotine. In using nicotinecontaining e-liquid, these individuals may rely on e-cigarettes to supplement other sources of nicotine.

Finally, half of young adults who used e-cigarettes without nicotine exclusively reported smoking conventional cigarettes and $31 \%$ reported ND symptoms.
However only $15 \%$ had used e-cigarettes to quit in the past year. Users of e-cigarettes without nicotine may believe as many do $[4,48]$, that e-cigarettes are safer and "healthier" than conventional cigarettes, they may use ecigarettes for psychosocial reasons and/or they may be attracted to the more than 7000 flavors $[7,49]$. Although many believe that the concentration of toxic chemicals released in e-cigarette vapor is lower than in regular cigarette smoke [50, 51], e-cigarette vapor contains highly oxidizing free-based nicotine, a form of nicotine that is considered highly addictive because it is easily absorbed [21, 52]. Further these products are often mislabelled so that users believe they are using nicotine-free products which actually contain nicotine [53]. Finally even nicotine-free e-cigarettes may be harmful [4] since

Table 4 Use of e-cigarettes as a cessation aid according to e-liquid used. NDIT Study 2017-20

\begin{tabular}{|c|c|c|c|c|}
\hline \multirow[t]{3}{*}{ E-liquid used } & \multirow[t]{3}{*}{$\mathrm{n}$} & \multicolumn{3}{|c|}{ Used e-cigarettes as a cessation aid } \\
\hline & & Ever & In past year & Perceived that e-cigarettes helped \\
\hline & & $\%$ & $\%$ & $\%$ \\
\hline Total & $138^{\mathrm{a}}$ & 44.2 & 29.0 & 16.7 \\
\hline One e-liquid & 85 & 40.0 & 25.9 & 14.1 \\
\hline With nicotine & 35 & 77.1 & 54.3 & 28.6 \\
\hline Without nicotine & 8 & 37.5 & 25.0 & 25.0 \\
\hline For cannabis & 42 & 9.5 & 2.4 & 0.0 \\
\hline Two e-liquids & 40 & 47.5 & 32.5 & 22.5 \\
\hline With and without nicotine & 19 & 63.2 & 47.4 & 26.3 \\
\hline With nicotine and for cannabis & 8 & 62.5 & 37.5 & 37.5 \\
\hline Without nicotine and for cannabis & 13 & 15.4 & 7.7 & 7.7 \\
\hline Three e-liquids & 13 & 61.5 & 38.5 & 15.4 \\
\hline
\end{tabular}

${ }^{a} 11$ participants who had never smoked cigarettes (verified with past surveys) were excluded from this table 
the aerosols in e-cigarettes without nicotine have been associated with acute endothelial cell dysfunction [54].

Most NDIT participants (80\%) who used e-cigarettes to help with cessation in the past year reported smoking in the past month, suggestive that e-cigarette use may not have helped many quit. Extant evidence on the efficacy of e-cigarettes is equivocal $[4,13,14,24,55]$. A US report using nationally representative data found that only $13 \%$ of young adult lifetime e-cigarette users reported using e-cigarettes as a cessation aid and these individuals were less likely to report cessation in the pastyear [56]. It is possible that, because of nicotine in ecigarettes (even in e-cigarettes labelled nicotine-free [53]), young adults who try to quit using nicotinecontaining e-cigarettes in fact contribute to or increase their ND level [25] leaving them craving nicotine. Polytobacco users in general, are more likely to report ND symptoms than cigarette-only smokers [25, 57]. One hypothesis posits that e-cigarette users could decrease the number of cigarettes smoked because e-cigarettes deliver nicotine at similar rates, making them as or more satisfying than traditional nicotine replacement therapies, but contributing more to ND and sustained smoking [25]. Olfson et al. (2019) [56] reported that e-cigarette users were 2.3 times more likely to be daily cigarette smokers than non-e-cigarette users, and 3.6 times more likely to report a tobacco use disorder. Recent longitudinal findings concur that dual use (cigarettes and e-cigarettes) was associated with an increase in e-cigarette frequency, nicotine exposure and ND in adolescent e-cigarette users with minimal cessation benefits [58]. In addition to the nicotine content of e-cigarettes, the "nicotine environment" of e-cigarette users likely represents an important barrier to cessation [37] and contributes to continued smoking and ND.

\section{Future directions}

The rising popularity of e-cigarettes among youth $[1,4$, $56,59]$ and increased availability of e-liquid with nicotine [2, 60], threatens tobacco control achievements [5]. Up to 2018, there were no regulations governing vaping products in Canada. In May 2018, the Tobacco and Vaping Products Act (TVPA) [2, 60] created a legal framework for regulating the sale, manufacture, labeling and promotion of vaping products sold in Canada including legalizing the sale of e-liquid containing nicotine. While e-cigarettes may help some smokers quit, the CDC does not recommend them for youth or people not currently using tobacco products [29]. Therefore monitoring trends in who uses which e-liquid types and the reasons for that choice is critical in terms of understanding the e-cigarette market and developing programs and policy that minimize negative impacts on health. Given changes in legislation and shifts from the original intent of e- cigarettes for cessation to their popularity for vaping cannabis, and with emerging vaping-related illness, program and policy makers and practitioners must remain abreast (or better yet, forecast) this rapidly evolving landscape to adequately prepare for the impact on health. Finally, practitioners must include vaping in their smoking cessation counselling [61].

\section{Limitations}

Limitations of this analysis include that the proportions estimated are imprecise because the sample of ecigarette users was small. Results may not be generalizable, although the proportion of e-cigarette users in NDIT mirrored national data, as did the observation that more males than females used e-cigarettes [1]. E-liquid content with respect to nicotine content was "perceived." Even if information on nicotine was available and participants remembered accurately, the nicotine content of e-liquid is often mislabeled [53]. Data for this study were collected pre- and post-TVPA, which could have increased access to e-cigarettes with nicotine. However, e-liquid with nicotine were widely available online and in stores prior to the TVPA [2,62]. Improved product labelling (i.e., including the concentration of nicotine, complete listings of ingredients on packages, presence of e-cigarette health warnings) following the TVPA could have impacted product choice. Results from a recent study [63] suggest that $28 \%$ of ecigarette users purchase their e-liquid online where regulations are not always adhered to [62, 63]. Evidence from Australia which banned the sale of nicotine vaping products, suggests that regulation is associated with increases in online sales of vaping products [63]. ND indicators measured ND pertaining to conventional cigarettes. Finally the study design was cross-sectional limiting causal inference.

\section{Conclusions}

A popular use of e-cigarettes in this 2017-20 sample of young adults was to vape cannabis. Relatively few used e-cigarettes for cessation and most used other nicotinecontaining substances including combustible cigarettes. Identification of emerging trends in e-cigarette use is needed to inform programs and policy.

\section{Abbreviations}

CDC: Centers for Disease Control and Prevention; ND: Nicotine dependence; NDIT Study: Nicotine Dependence in Teens Study;" SD: Standard deviation;" THC: Tetrahydrocannabinol; TVPA: Tobacco and Vaping Products Act

\section{Acknowledgements}

Jennifer O'Loughlin holds a Canada Research Chair in the Early Determinants of Adult Chronic Disease. The authors thank the Nicotine Dependence in Teens Study participants. 


\section{Authors' contributions}

ED reviewed the literature, conducted data analysis, contributed to the design of the analysis and interpretation of data, and drafted the article. MPS contributed to the design of the analysis and interpretation of data. JOL designed the study, obtained the funding, developed the survey instruments, supervised data collection, contributed to the design of the analysis and interpretation of data, coordinated drafting the article, and wrote sections of the article. All authors reviewed the article critically, approved the final version, and are responsible for the reported research.

\section{Funding}

This work was supported by the Canadian Cancer Society (grant numbers 010271, 017435, 704031). The funders were not involved in the design or conduct of the study; collection, management, analysis, or interpretation of the data; or preparation, review, or approval of the manuscript.

\section{Availability of data and materials}

Data are available upon request. To gain access, applicants must complete a data access form available on our Nicotine Dependence in Teens website (www.nditstudy.ca) and return it to the principal investigator (jennifer. oloughlin@umontreal.ca).

The procedure to obtain access to Nicotine Dependence in Teens data is described in O'Loughlin, J., Dugas, E. N., Brunet, J., DiFranza, J., Engert, J. C., Gervais, A., Gray-Donald, K., Karp, I., Low, N. C., Sabiston, C., Sylvestre, M. P., Tyndale, R. F., Auger, N., Belanger, M., Barnett, T., Chaiton, M., Chenoweth, M. J., Constantin, E., Contreras, G., Kakinami, L., Labbe, A., Maximova, K., McMillan, E., O'Loughlin, E. K., Pabayo, R., Roy-Gagnon, M. H., Tremblay, M., Wellman, R. J., Hulst, A., Paradis, G., 2015. Cohort Profile: The Nicotine Dependence in Teens (NDIT) Study. Int J Epidemiol. 44(5), 1537-1546. doi: https://doi.org/10. 1093/ije/dyu135. The relevant paragraph is described below. This process has been approved by the ethics committee at the CRCHUM.

Access to Nicotine Dependence in Teens data is open to any universityappointed or affiliated investigator upon successful completion of the application process. Masters, doctoral and postdoctoral students may apply through their primary supervisor. For more information, visit www.nditstudy. ca or contact the Principal Investigator.

\section{Ethics approval and consent to participate}

All students provided assent and parents or guardians provided written informed consent. The study was approved by the Direction de santé publique de Montreal-Centre, the McGill University and the Centre de Recherche du Centre Hospitalier de l'Université de Montréal Ethics Review Boards.

\section{Consent for publication}

Not applicable.

\section{Competing interests}

The authors declare that they have no competing interests.

Received: 25 November 2019 Accepted: 4 June 2020

Published online: 12 June 2020

\section{References}

1. Reid JL, Hammond D, Tariq U, Burkhalter R, Rynard VL, Douglas O. Tobacco use in Canada: patterns and trends, 2019 Edition. Waterloo: Propel Centre for Population Health Impact, University of Waterloo; 2019. https:// uwaterloo.ca/tobacco-use-canada/sites/ca.tobacco-use-canada/files/uploads/ files/tobacco_use_in_canada_2019.pdf. Accessed Oct 202019.

2. Hammond D, Reid JL, Rynard VL, Fong GT, Cummings KM, McNeill A, et al. Prevalence of vaping and smoking among adolescents in Canada, England, and the United States: repeat national cross sectional surveys. BMJ. 2019; 365:I2219. https://doi.org/10.1136/bmj.12219.

3. Dai $\mathrm{H}$, Leventhal AM. Prevalence of e-cigarette use among adults in the United States, 2014-2018. JAMA. 2019. https://doi.org/10.1001/jama.2019. 15331 [Epub ahead of print].

4. U.S. Department of Health and Human Services. E-cigarette use among youth and young adults. A report of the surgeon general. 2016. https://ecigarettes.surgeongeneral.gov/documents/2016_sgr_full_report_non-508. pdf. Accessed Oct 202019.
5. Jenssen BP, Walley SC. E-cigarettes and similar devices. Pediatrics. 2019; 143(2):e20183652. https://doi.org/10.1542/peds.2018-3652.

6. Bhatnagar A, Whitsel LP, Ribisl KM, Bullen C, Chaloupka F, Piano MR, et al. Electronic cigarettes: a policy statement from the American Heart Association. Circulation. 2014;130(16):1418-36. https://doi.org/10.1161/CIR. 0000000000000107.

7. Tierney PA, Karpinski CD, Brown JE, Luo W, Pankow JF. Flavour chemicals in electronic cigarette fluids. Tob Control. 2016;25(e1):e10-5. https://doi.org/10. 1136/tobaccocontrol-2014-052175.

8. Kenne DR, Fischbein RL, Tan AS, Banks M. The use of substances other than nicotine in electronic cigarettes among college students. Subst Abus. 2017; 11:1178221817733736. https://doi.org/10.1177/1178221817733736.

9. Spindle TR, Cone EJ, Schlienz NJ, Mitchell JM, Bigelow GE, Flegel R, et al. Acute effects of smoked and vaporized cannabis in healthy adults who infrequently use cannabis: a crossover trial. JAMA Netw Open. 2018;1(7): e184841. https://doi.org/10.1001/jamanetworkopen.2018.4841.

10. Cassidy RN, Meisel MK, DiGuiseppi G, Balestrieri S, Barnett NP. Initiation of vaporizing cannabis: individual and social network predictors in a longitudinal study of young adults. Drug Alcohol Depend. 2018;188:334-40. https://doi.org/10.1016/j.drugalcdep.2018.04.014.

11. Morean ME, Lipshie N, Josephson M, Foster D. Predictors of adult e-cigarette users vaporizing cannabis using e-cigarettes and vape-pens. Subst Use Misuse. 2017;52(8):974-81. https:/doi.org/10.1080/10826084.2016.1268162.

12. Frohe T, Leeman RF, Patock-Peckham J, Ecker A, Kraus S, Foster DW. Correlates of cannabis vape-pen use and knowledge among U.S. college students. Addict Behav Rep. 2018;7:32-9. https://doi.org/10.1016/j.abrep.2017.11.004.

13. Hartmann-Boyce J, McRobbie H, Bullen C, Begh R, Stead LF, Hajek P. Electronic cigarettes for smoking cessation. Cochrane Database Syst Rev. 2016;9:CD010216. https://doi.org/10.1002/14651858.CD010216.pub3.

14. Kalkhoran S, Glantz SA. E-cigarettes and smoking cessation in real-world and clinical settings: a systematic review and meta-analysis. Lancet Respir Med. 2016;4(2):116-28. https://doi.org/10.1016/S2213-2600(15)00521-4.

15. Patil S, Arakeri G, Patil S, Ali Baeshen H, Raj T, Sarode SC, et al. Are electronic nicotine delivery systems (ENDs) helping cigarette smokers quit?-current evidence. J Oral Pathol Med. 2019. https://doi.org/10.1111/jop.12966 [Epub ahead of print].

16. Worku D, Worku E. A narrative review evaluating the safety and efficacy of e-cigarettes as a newly marketed smoking cessation tool. SAGE Open Med. 2019;7:2050312119871405. https://doi.org/10.1177/2050312119871405 eCollection 2019.

17. Hajek P, Phillips-Waller A, Przulj D, Pesola F, Myers Smith K, Bisal N, et al. A randomized trial of E-cigarettes versus nicotine-replacement therapy. $\mathrm{N}$ Engl J Med. 2019;380(7):629-37. https://doi.org/10.1056/NEJMoa1808779.

18. Halpern SD, Harhay MO, Saulsgiver K, Brophy C, Troxel AB, Volpp KG. A pragmatic trial of E-cigarettes, incentives, and drugs for smoking cessation. N Engl J Med. 2018;378(24):2302-10. https://doi.org/10.1056/ NEJMsa1715757.

19. Brown J, Shahab L, West R. Does the offer of e-cigarettes benefit smoking cessation among unselected smokers? Addiction. 2019;114(1):186-7. https://doi.org/10.1111/add.14415.

20. Harhay MO, Troxel AB, Volpp KG, Halpern SD, Response to Brown, et al. Does the offer of e-cigarettes benefit smoking cessation among unselected smokers? Addiction. 2019 Jan;114(1):187-8. https:/doi.org/10.1111/add.14460.

21. Soneji S, Barrington-Trimis JL, Wills TA, Leventhal AM, Unger JB, Gibson LA, et al. Association between initial use of e-cigarettes and subsequent cigarette smoking among adolescents and young adults: a systematic review and meta-analysis. JAMA Pediatr. 2017;171(8):788-97 https://doi.org/ 10.1001/jamapediatrics.2017.1488

22. Barrington-Trimis JL, Kong G, Leventhal AM, Liu F, Mayer M, Cruz TB, et al. Ecigarette use and subsequent smoking frequency among adolescents. Pediatrics. 2018;142(6):e20180486 https://doi.org/10.1542/peds.2018-0486.

23. Spindle TR, Hiler MM, Cooke ME, Eissenberg T, Kendler KS, Dick DM. Electronic cigarette use and uptake of cigarette smoking: a longitudinal examination of U.S. college students. Addict Behav. 2017;67:66-72. https://doi.org/10.1016/j.addbeh.2016.12.009.

24. Zhuang YL, Cummins SE, Sun JY, Zhu SH. Long-term e-cigarette use and smoking cessation: a longitudinal study with U.S. population. Tob Control. 2016, 25;(Suppl 1):i90-5. https://doi.org/10.1136/tobaccocontrol-2016053096

25. Martínez Ú, Martínez-Loredo V, Simmons VN, Meltzer LR, Drobes D, Brandon $\mathrm{KO}$, et al. How does smoking and nicotine dependence change 
after onset of vaping? A Retrospective analysis of dual users. Nicotine Tob Res. 2019:ntz043. https://doi.org/10.1093/ntr/ntz043.

26. Mirbolouk M, Charkhchi P, Kianoush S, Uddin SMI, Orimoloye OA, Jaber R, et al. Prevalence and distribution of E-cigarette use among U.S. adults: behavioral risk factor surveillance system, 2016. Ann Intern Med. 2018;169(7): 429-38. https://doi.org/10.7326/M17-3440

27. Perrine CG, Pickens CM, Boehmer TK, King BA, Jones CM, DeSisto CL, et al. Characteristics of a multistate outbreak of lung injury associated with ecigarette use, or vaping - United States, 2019. MMWR Morb Mortal Wkly Rep. 2019;68(39):860-4 https://doi.org/10.15585/mmwr.mm6839e1.

28. CBC News. Quebec resident confirmed as first Canadian case of vapingrelated illness. CBC/Radio-Canada. 2019. https://www.cbc.ca/news/canada/ montreal/vaping-related-illness-quebec-1.5299487. Accessed Oct 202019.

29. U.S. Department of Health \& Human Services. Outbreak of Lung Injury Associated with E-Cigarette Use, or Vaping. CDC Centers for Disease Control and Prevention. 2019. https://www.cdc.gov/tobacco/basic_information/ecigarettes/severe-lung-disease.html. Accessed Oct 202019.

30. O'Loughlin J, Dugas EN, Brunet J, DiFranza J, Engert JC, Gervais A, et al. Cohort profile: the nicotine dependence in teens (NDIT) study. Int J Epidemiol. 2014;44(5):1537-46. https://doi.org/10.1093/ije/dyu135.

31. Schlam TR, Piper ME, Cook JW, Fiore MC, Baker TB. Life 1 year after a quit attempt: real-time reports of quitters and continuing smokers. Ann Behav Med. 201;44(3):309-19. https://doi.org/10.1007/s12160-012-9399-9.

32. Prokhorov AV, Hudmon KS, Cinciripini PM, Marani S. "withdrawal symptoms" in adolescents: a comparison of former smokers and never-smokers. Nicotine Tob Res. 2005;7(6):909-13.

33. Bélanger M, O'Loughlin J, Okoli CT, McGrath JJ, Setia M, Guyon L, et al. Nicotine dependence symptoms among young never-smokers exposed to secondhand tobacco smoke. Addict Behav. 2008;33(12):1557-63. https://doi. org/10.1016/j.addbeh.2008.07.011.

34. Racicot S, McGrath JJ, O'Loughlin J. An investigation of social and pharmacological exposure to secondhand tobacco smoke as possible predictors of perceived nicotine dependence, smoking susceptibility, and smoking expectancies among never-smoking youth. Nicotine Tob Res. 2011; 13(10):926-33. https://doi.org/10.1093/ntr/ntr100.

35. O'Loughlin J, DiFranza J, Tarasuk J, Meshefedjian G, McMillan-Davey E, Paradis $\mathrm{G}$, et al. Assessment of nicotine dependence symptoms in adolescents: a comparison of five indicators. Tob Control. 2002;11(4):354-60. https://doi.org/10.1136/tc.11.4.354.

36. Crookston BT, Forste R, McClellan C, Georgiadis A, Heaton TB. Factors associated with cognitive achievement in late childhood and adolescence: the young lives cohort study of children in Ethiopia, India, Peru, and Vietnam. BMC Pediatr. 2014;14(1):253. https://doi.org/10.1186/1471-2431-14-253.

37. Korupp SE, Ganzeboom HB, Van Der Lippe T. Do mothers matter? A comparison of models of the influence of mothers' and fathers' educational and occupational status on children's educational attainment. Qual Quant. 2002;36(1):17-42. https://doi.org/10.1023/A:1014393223522.

38. Hartwell G, Thomas S, Egan M, Gilmore A, Petticrew M. E-cigarettes and equity: a systematic review of differences in awareness and use between sociodemographic groups. Tob Control. 2017;26(e2):e85-91. https://doi.org/ 10.1136/tobaccocontrol-2016-053222.

39. Trivers KF, Phillips E, Gentzke AS, Tynan MA, Neff $\amalg$. Prevalence of cannabis use in electronic cigarettes among U.S. youth. JAMA Pediatr. 2018;172(11): 1097-9. https://doi.org/10.1001/jamapediatrics.2018.1920.

40. Kowitt SD, Osman A, Meernik C, Zarkin GA, Ranney LM, Martin J, et al. Vaping cannabis among adolescents: prevalence and associations with tobacco use from a cross-sectional study in the USA. BMJ Open. 2019;9(6): e028535. https://doi.org/10.1136/bmjopen-2018-028535.

41. Jones $\mathrm{CB}$, Meier $\mathrm{MH}$, Pardini DA. Comparison of the locations where young adults smoke, vape, and eat/drink cannabis: implications for harm reduction. Addict Behav Rep. 2018;8:140-6. https://doi.org/10.1016/j.abrep.2018.09.002.

42. Etter JF. Are long-term vapers interested in vaping cessation support? Addiction. 2019;114(8):1473-7. https://doi.org/10.1111/add.14595.

43. Grégoire MC. Vaping risks for youth continue to emerge. CMAJ. 2019; 191(40):E1113-4. https://doi.org/10.1503/cmaj.1095807.

44. Romberg AR, Miller Lo EJ, Cuccia AF, Willett JG, Xiao H, Hair EC, et al. Patterns of nicotine concentrations in electronic cigarettes sold in the United States, 2013-2018. Drug Alcohol Depend. 2019;203:1-7. https://doi. org/10.1016/j.drugalcdep.2019.05.029.
45. Government of Canada. Proposals for the regulation of vaping products. 2017. https:/www.canada.ca/content/dam/hc-sc/documents/programs/ consultation-regulation-vaping-products/pub1-eng.pdf. Accessed Oct 202019.

46. News CBC. Vapes need same restrictions as tobacco, medical groups tell federal parties: CBC/Radio-Canada; 2019. https://www.cbc.ca/news/health/ vaping-thursday-1.5289485. Accessed Oct 202019.

47. Congress.gov. H.R.4624 - Ending Nicotine Dependence from Electronic Nicotine Delivery Systems Act of 2019. 2019. https://www.congress.gov/ bill/116th-congress/house-bill/4624/text. Accessed Oct 202019.

48. Kong G, Morean ME, Cavallo DA, Camenga DR, Krishnan-Sarin S. Reasons for electronic cigarette experimentation and discontinuation among adolescents and young adults. Nicotine Tob Res. 2014;17(7):847-54. https:// doi.org/10.1093/ntr/ntu257.

49. McNeill A, Brose LS, Calder R, Bauld L, Robson D. Vaping in England: an evidence update February 2019. In: A report commissioned by Public Health England: Public Health England; 2019. www.gov.uk/ government/ publications/vaping-in-england-an-evidence-updatefebruary-2019.

50. Goniewicz ML, Smith DM, Edwards KC, Blount BC, Caldwell KL, Feng J, et al. Comparison of nicotine and toxicant exposure in users of electronic cigarettes and combustible cigarettes. JAMA Netw Open. 2018;1(8):e185937. https://doi.org/10.1001/jamanetworkopen.2018.5937.

51. Farsalinos KE, Polosa R. Safety evaluation and risk assessment of electronic cigarettes as tobacco cigarette substitutes: a systematic review. Ther Adv Drug Saf. 2014;5(2):67-86. https://doi.org/10.1177/2042098614524430.

52. Goel R, Durand E, Trushin N, Prokopczyk B, Foulds J, Elias RJ, et al. Highly reactive free radicals in electronic cigarette aerosols. Chem Res Toxicol. 2015 Sep 21;28(9):1675-7. https://doi.org/10.1021/acs.chemrestox.5b00220.

53. Pagano T, Bida MR, Robinson RJ. Laboratory activity for the determination of nicotine in electronic cigarette liquids using gas chromatography-mass spectrometry. J Lab Chem Educ. 2015;3(3):37-43.

54. National Academies of Sciences, Engineering, and Medicine. Public health consequences of e-cigarettes. Washington, DC: The National Academies Press; 2018. https://doi.org/10.17226/24952.

55. Wallace AM, Foronjy RE. Electronic cigarettes: not evidence-based cessation. Transl Lung Cancer Res. 2019;8(Suppl 1):S7-S10. https://doi.org/10.21037/ tlcr.2019.03.08

56. Olfson M, Wall MM, Liu SM, Sultan RS, Blanco C. E-cigarette use among young adults in the U.S. Am J Prev Med. 2019;56(5):655-63. https://doi.org/ 10.1016/j.amepre.2018.12.004.

57. Loukas A, Chow S, Pasch KE, Li X, Hinds II, Josephine T, et al. College students' polytobacco use, cigarette cessation, and dependence. Am J Health Behav. 2016;40(4):514-22. https://doi.org/10.5993/AJHB.40.4.13.

58. Vogel EA, Prochaska JJ, Ramo DE, Andres J, Rubinstein ML. Adolescents' ecigarette use: increases in frequency, dependence, and nicotine exposure over 12 months. J Adolesc Health. 2019;64(6):770-5. https://doi.org/10.1016/ j.jadohealth.2019.02.019.

59. Shiplo S, Czoli CD, Hammond D. E-cigarette use in Canada: prevalence and patterns of use in a regulated market. BMJ Open. 2015;5(8):e007971. https:// doi.org/10.1136/bmjopen-2015-007971.

60. Government of Canada. Tobacco and Vaping Products Act. 2018. https:// www.canada.ca/en/health-canada/services/health-concerns/tobacco/ legislation/federal-laws/tobacco-act.html. Accessed Feb 32020.

61. Christiani CD. Vaping-Induced Lung Injury. N Engl J Med. 2019. https://doi org/10.1056/NEJMe1912032.

62. Hammond D, White CM, Czoli CD, Martin CL, Magennis P, Shiplo S. Retail availability and marketing of electronic cigarettes in Canada. Can J Public Health. 2015;106:e408-12. https://doi.org/10.17269/CJPH.106.5105.

63. Braak DC, Cummings KM, Nahhas GJ, Heckman BW, Borland R, Fong GT, et al. Where Do Vapers Buy Their Vaping Supplies? Findings from the International Tobacco Control (ITC) 4 Country Smoking and Vaping Survey. Int J Environ Res Public Health. 2019;16(3):E338. https://doi.org/10.3390/ ijerph 16030338 .

\section{Publisher's Note}

Springer Nature remains neutral with regard to jurisdictional claims in published maps and institutional affiliations. 